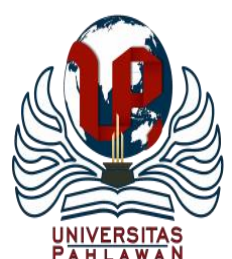

Jurnal Abdidas Volume 2 Nomor 5 Tahun 2021 Halaman 1133 - 1138

JURNAL ABDIDAS

http://abdidas.org/index.php/abdidas

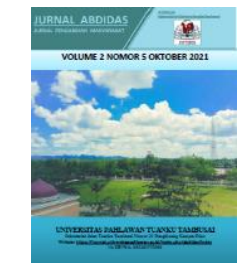

\title{
Sosialisasi Penggunaan Google Classroom sebagai Media Pembelajaran Online
}

\author{
Lasma Siagian \\ Pendidikan Ekonomi, Universitas HKBP Nommensen Pematangsiantar, Indonesia \\ Email : siagianlasma95@gmail.com
}

\begin{abstract}
Abstrak
Pesatnya perkembangan teknologi saat ini dapat mempengaruhi dunia pendidikan. Guru dituntut memiliki kemampuan yang cukup dalam mengikuti perkembangan teknologi. Salah satu pengaruh positif teknologi sebagai penunjang pendidikan yaitu pemanfaatan media e-learning berbasis Google Classroom sebagai media pembelajaran. Pengabdian masyarakat bertujuan untuk meningkatkan wawasan dan keterampilan guru dalam menggunakan aplikasi Google Classroom sebagai media pembelajaran jarak jauh. Salah satu solusi dalam pembelajaran jarak jauh adalah dengan menggunakan Google Classroom sebagai media yang memudahkan guru dan peserta didik dalam melakukan proses belajar mengajar di rumah. Pemanfaatan Google Classroom saat ini sangat efisien dan efektif yang tidak terbatas oleh ruang dan waktu. Guru dapat memberikan materi secara online baik berupa teks, gambar, audio, maupun video kepada peserta didik. Mitra yang terlibat dalam pengabdian ini adalah guru guru di SMK Yapim Sei Rotan. Hasil kegiatan menunjukkan bahwa peserta pelatihan sudah memahami langkah-langkah dan bagaimana cara menggunakan aplikasi google classroom.
\end{abstract}

Kata kunci: google classroom, pembelajaran online, teknologi

\begin{abstract}
Information technology development significantly changed the education system. Teachers are required to improve their knowledge and skills to adapt to the current information and technology development. Google Classroom is one of internet-based-learning that supports distance learning and has become a common learning tool in the 21st century. This research aims to improve teachers' knowledge and skills in using Google Classroom as a distance learning tool. The unlimited access to educational material and simplify the teaching and learning process are some of the benefits of using Google Classroom. In addition, it helps teachers to post text based materials or interactive image, audio, and video materials to the students. The partners of this research are teachers at Senior Vocational High School Yapim Sei Rotan. The results of the activity showed that the trainees understood the steps using Google classroom applications.
\end{abstract}

Keywords: google classroom, online learning, technology

Copyright (c) 2021 Lasma Siagian

$\triangle$ Corresponding author

Address : Jl. Limau Manis Gg. Bengkel Tanjung Morawa

Email : siagianlasma95@gmail.com

DOI : https://doi.org/10.31004/abdidas.v2i5.439

ISSN 2721- 9224 (Media Cetak)

ISSN 2721- 9216 (Media Online) 


\section{PENDAHULUAN}

Perkembangan teknologi yang terjadi begitu cepat telah mengubah hampir seluruh tatanan kehidupan sosial, mulai dari kegiatan ekonomi dengan penggunaan uang elektrik, pemanfaatan transportasi berbasis daring, sampai pada pemanfaatan teknologi dibidang pendidikan dengan dikenalkannya pembelajaran online/daring. Di Indonesia, pemanfaatan pembelajaran berbasis daring (online) sudah cukup dikenal. Media pembelajaran online memiliki peran yang sangat singnifikan dalam menentukan kelancaran proses kegiatan belajar mengajar tanpa tatap muka secara langsung. Media pembelajaran dapat berupa teknologi yang memanfaatkan internet maupun aplikasi yang ada. Penerapan media pembelajaran sangat membantu keberhasilan dalam proses belajar mengajar (Soni, et al., 2018). Dalam kondisi pandemi saat ini, maka media pembelajaran online menjadi alternatif untuk tetap melaksanakan kegiatan belajar mengajar. Salah satu media yang digunakan yaitu Google Classroom yang berguna untuk berbagi dokumen. Penggunaan media pembelajaran bisa membangkitkan keinginan, minat baru, dapat memotivasi dan merangsang kegiatan belajar bahkan mempengaruhi psikologis peserta didik (Soni, et al., 2018), teknologi dan media bisa berperan banyak untuk belajar. Jika pengajarannya berpusat pada guru, teknologi dan media digunakan untuk mendukung penyajian pengajaran. Di sisi lain, apabila pengajaran berpusat pada peserta didik, para peserta didik merupakan pengguna utama teknologi dan media.
Banyak media online yang bisa digunakan untuk mengganti kegiatan belajar mengajar dikelas. Salah satunya menggunakan media Google Classroom. Pemanfaatan Google Classroom dapat dilakukan di Komputer, Laptop, Tab dan Handphone. Sehingga aplikasi ini dapat lebih mudah untuk diterapkan dan disesuaikan dengan kondisi yang ada.

Google classroom adalah aplikasi yang dibuat oleh google yang bertujuan untuk membantu pendidik dan peserta didik dalam proses pembelajaran. Google Classroom merupakan inovasi dari Google For Education yang menarik karena merupakan produk yang dibuat untuk mendampingi guru dan siswa dalam melaksanakan kegiatan belajar mengajar. Google classroom membantu guru untuk membuat dan mengatur tugas kelas dengan cepat dan mudah, memberikan umpan balik kepada siswa langsung secara efisien, dan berkomunikasi bersama siswa tanpa terbatas oleh ruang dan waktu. Google Classroom dianggap sebagai platform terbaik yang mampu meningkatkan kinerja guru. Google Classroom menyediakan fasilitas yang sangat bermanfaat yang dapat dimanfaatkan oleh siswa.

$$
\text { Melalui aplikasi Google Classroom }
$$
diasumsikan bahwa tujuan pembelajaran akan lebih mudah direalisasikan dan sarat kebermaknaan. Oleh karena itu, penggunaan Google Classroom ini sesungguhnya mempermudah guru dalam mengelola pembelajaran dan menyampaikan informasi secara tepat dan akurat kepada peserta didik (Hakim, 2016). 


\section{METODE}

Kegiatan pengabdian ini melibatkan guruguru SMK Yapim Taruna Sei Rotan sebagai peserta, dimana kegiatan pengabdian ini dilakukan selama 2 hari yaitu dimulai pada tanggal 13 dan tanggal 14 Januari 2021.

Metode pendekatan yang digunakan dalam kegiatan pengabdian ini adalah dalam bentuk pelatihan dengan tahapan-tahapan kegiatann sebagai berikut: a. Presentasi, dilakukan di hari pertama yaitu tanggal 13 Januaru 2021. Kegiatan ini diawali dengan penjelasan tentang: 1) pengertian, fungsi dan manfaat google classroom dalam proses pembelajaran, 2) komponen komponen dalam pembuatan google classroom. b. Praktek, dilakukan di hari kedua yaitu pada tanggal 14 Januari 2021. Setelah semua peserta memahami dengan baik aplikasi google classroom, lalu masuk kepada sesi pembuatan akun google classroom, teknik mengupload materi, tugas, baik dalam bentuk audio, video, youtube. C. Tanya jawab, semua peserta pelatihan diberikan kesempatan untuk bertanya mengenai aplikasi google classroom baik yang disampaikandalam bentuk preserntasi maupun hal yang berkaitan dengan praktek pembuatan google classroom.

\section{HASIL DAN PEMBAHASAN}

Hasil kegiatan pelatihan penggunaan google classroom sebagai media pembelajaran yang dilakukan secara online dapat dijabarkan sebagai berikut:

Sesi pemaparan materi di ikuti oleh guruguru SMK Yapim Sei Rotan dan sangat antusias menerima materi yang disampaikan.

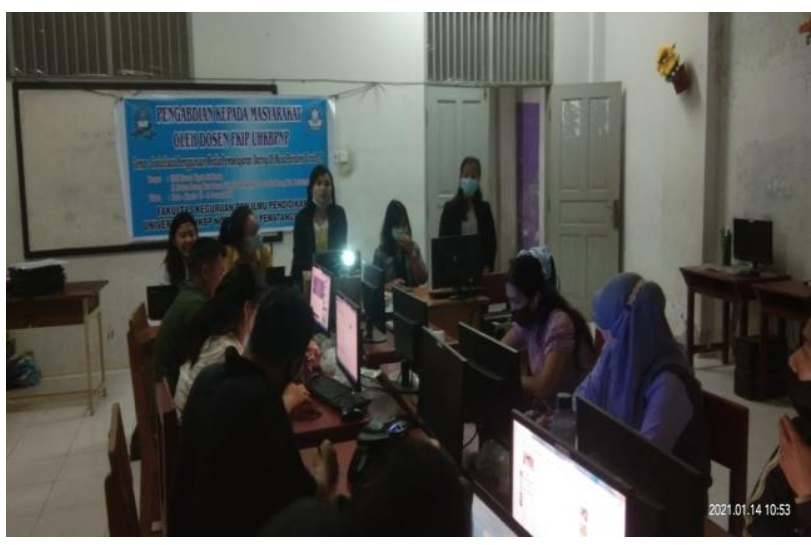

Gambar 1. Pemaparan Materi

Sesi kedua merupakan praktek langsung membuat google classroom. Pada saat praktek pembuatan google classroom berlangsung, guru guru sangat antusias dan tertarik untuk mencoba membuat akun google classroom, karena aplikasi ini merupakan salah satu aplikasi yang sangat bermanfaat baik bagi guru maupun peserta didik dalam melaksanakan proses pemelajaran yang dilakukan secara daring atau online.

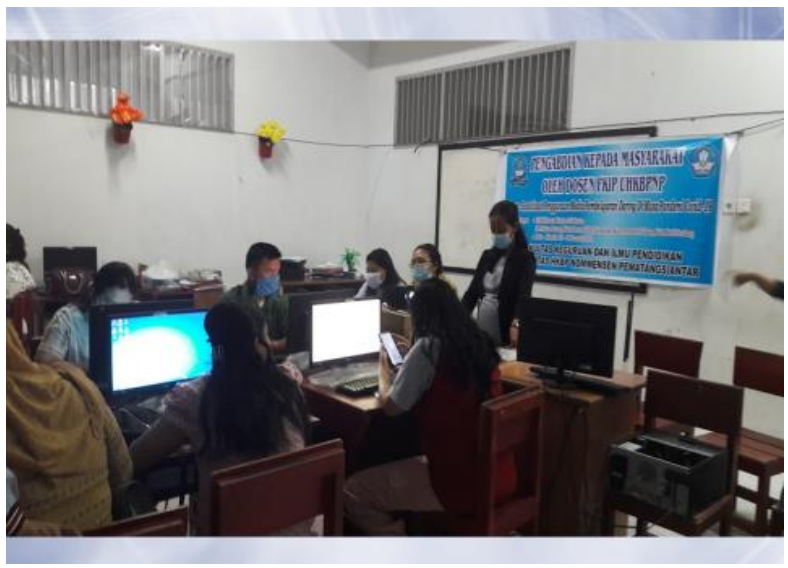

Gambar 2. Praktek pembuatan akun google classroom 


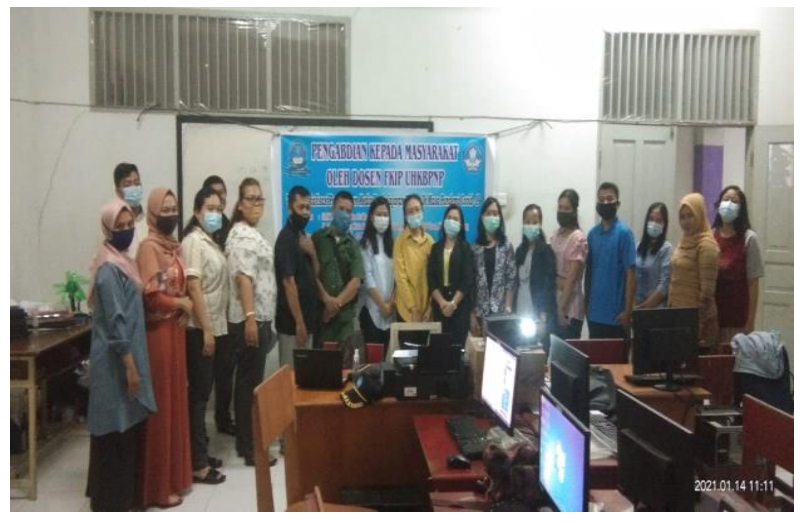

Gambar 3. Peserta Sosialisasi

Salah satu media e-learning yang dapat digunakan saat ini adalah Google Classoom karena Google Classroom dianggap sebagai salah satu platform terbaik. Pembelajaran dengan e-learning dapat bermanfaat untuk meningkatkan efektivitas dan fleksibilitas pembelajaran karena melalui $e$ learning materi pembelajaran dapat di akses kapan saja dan dari mana saja dan disamping itu juga materi yang dapat diperkaya dengan berbagai sumber belajar termasuk multimedia dengan cepat dapat diperbaharui oleh pengajar (Maryani,2013). Menurut (Deviyanti,2020) mengatakan bahwa Google Classroom merupakan media pembelajaran berbasis jejaring sosial untuk mendukung dalam proses pembelajaran pada kelas virtual, dimana google classroom menyediakan fasilitas untuk berbagi materi,berkomunikasi dan berdiskusi dengan teman maupun guru serta mengerjakan tugas secara online yang dapat digunakan kapan saja dan dimana saja.

Sebelum menggunakan Google Classroom diharapkan pengajar untuk mendemostrasikan dalam penggunaannya kepada peserta didik agar peserta didik tidak mengalami kebingungan saat melakukan proses kegiatan belajar mengajar dengan google classroom yang banyak sekali fitur yang di dalamnya agar tidak terjadi kesalahan dan dalam menggunakan media google classroom ini haruslah dirancang sedemikan rupa agar terciptanya proses pembelajaran yang baik dengan memiliki tahapan perancangan dimana pengajar membuat rencana pembelajaran, jenis kegiatan dan rencana kegiatan apa yang akan digunakan dalam pembelajaran menggunakan google classroom, kemudian tahap implementasi dimana pengajar membuat sebuah kelas yang ada di dalam google classroom seperti materi yang dirancang pengajar dengan baik yang akan diberikan ke dalam kelas tersebut yang berupa berbentuk power point, bahan ajar, video dan segala sumber yang dapat dibagikan di dalam Google Classroom lalu penyampaian pembelajaran, interaksi pembelajaran, dan pada tahap terakhir melakukan evaluasi pelaksanaan yaitu dimana saat pesera didik mendapatkan tugas untuk dikumpulkan sesuai waktu yang sudah dicatat oleh pengajar.

Setelah melakukan kegiatan pelatihan tentang Google Classroom ada beberapa penemuan yang didapatkan diantaranya adalah:

Pertama, sebagian guru belum menggunakan aplikasi Google Classroom sebagai media pembelajaran, sehingga para guru belum memanfaatkan penggunaan teknologi tersebut dalam pengelolaan kelasnya. Pemateri menjelaskan terlebih dahulu apa itu Google Classroom dan apa saja keunggulan ketika menggunakan Google Classroom. Kemudian, pemateri menjelaskan bagaimana cara membuat akun Google Classroom. Berikut ini cara masuk ke Google Classroom adalah: 
1. Buka browser kemudian ketik Google Classroom. Pemateri memastikan bahwa para guru sudah memiliki akun google. Setelah itu akan muncul halaman $\log$ in dan kemudian guru memasukkan akun google nya.

2. Jika sudah berhasil, pada halaman akun google akan terdapat pilihan yaitu log in sebagai guru dan siswa. Pilih sebagai guru.

3. Kemudian, pada halaman beranda akan muncul tanda + , klik untuk membuat kelas. Isi nama kelas, mata pelajaran dan ruangan kelas.

4. Setelah itu, guru bisa memilih informasi apa saja yang akan disampaikan dikelas. Ada pengumuman, tugas, pertanyaan.

5. Guru kemudian membagikan kode kelas untuk siswanya dan siswa mengikuti langkah diawal tapi gabung sebagai siswa.

6. Siswa yang sudah bergabung dikelas dapat terlihat di daftar siswa di halaman google classroom. Setelah dipandu oleh pemateri dan tim untuk membuat akun google classroom. Untuk lebih memudahkan para guru dibuat dalam lima kelompok dan para guru langsung membuat akun Google Classroom.

Kedua, para guru sangat antusias untuk membuat Google Classroom. Para guru jadi lebih mudah untuk melihat dan memeriksa hasil tugas siswa tanpa harus membawa kertas yang banyak. Kemudian, para siswa juga lebih mudah untuk melihat hasil feedback yang diberikan oleh guru dimana saja, karena Google classroom dapat diakses dimana saja tidak hanya disekolah tapi bisa juga di rumah. Ketiga, Semua data sudah tersimpan di akun google. Hal ini dapat membuat pembelajaran menjadi lebih efektif dan efisien. Keempat, guru dapat menjalin komunikasi dan kerjasama yang baik dengan siswanya. Karena siswa dapat mengunggah dan menanyakan hal apa saja yang kurang mereka pahami khususnya materi dikelas tersebut. Guru juga bisa langsung menjelaskan ketika ada siswa yang tidak paham. Kelima, penggunaan Google Classroom mendukung juga program pemerintah tentang go green. Hal ini terlihat dengan pengurangan penggunaan kertas yang digunakan dalam pengumpulan tugas.

Penggunaan Google Classroom dalam proses pembelajaran efektif dan praktis untuk digunakan sebagai proses kegiatan pembelajaran, karena Google Classroom memiliki tampilan atau fitur yang ada di dalamnya yang disediakan Google Classroom ini berupa proses mengajar, memberikan pertanyaan, memberikan tugas, serta membuat pengumuman. Dan tidak hanya itu saja Google Classroom juga menyediakan layanan multimedia (video streaming) untuk ditonton dan mendalami tentang pemahaman materi yang disampaikan karena Google Classroom dirancang sebagai media yang mampu berinteraksi langsung sehingga pemahaman materi lebih mudah dan dipahami pembelajar dan merupakan media platform yang mudah di akses dan merupakan inovatif yang merupakan salah satu platform online terbaik untuk belajar mengajar.

Secara umum pelaksanaan kegiatan pelatihan terhadap para guru berjalan baik dan lancar. Hal ini membuktikan bahwa pelatihan ini 
memberikan manfaat kepada para guru dan membantu mereka untuk mengimplemntasikannya dikelas. Ini bertujuan untuk meningkatkan kualitas pembelajaran agar tercapainya tujuan pembelajaran. Ini sesuai dengan teorinya bahwa penggunaan teknologi memberikan dampak positif dalam pembelajaran (Megahantara, 2017).

\section{SIMPULAN}

Pelatihan Google Classroom kepada guruguru di SMK Yapim Sei Rotan memberikan manfaat yang luar biasa untuk para guru dimana dengan diadakannya pelatihan tersebut maka bertambah juga pengetahuan guru di SMK Yapim Sei Rotan tentang pembelajaran e-learning dan terampil dalam menggunakan Google Classroom sebagai media pembelajaran online yang interaktif dan menyenangkan dalam proses pembelajaran.

\section{DAFTAR PUSTAKA}

Asyhar, R., (2012). Kreatif Mengembangkan Media Pembelajaran.

Deviyanti, Dkk. (2020). Pengembangan Media Elearning Berbasis Google Classroom Untuk Hmeningkatkan Hasil Belajar Siswa Pada Mata Pelajaran Ekonomi Kelas Xi Di Sma Unggul Sakti Jambi. Jurnal Manajemen Pendidikan Dan Ilmu Sosial, Vol. 1, No. 1: 303-316.

(Https://Doi.Org/10.38035/Jmpis.V1i1.264).

Gunawan, Sunarman. (2018). Pengembangan

Kelas Virtual Dengan Google Classroom Dalam Keterampilan Pemecahan Masalah (Problem Solving) Topik Vektor Pada Siswa Smk Untuk Mendukung Pembelajaran. Prosiding Seminar Nasional Etnomatnesia: 340-348.

(Http://Jurnal.Ustjogja.Ac.Id/Index.Php

Hanum, N.S., (2013). Keefetifan E-Learning Sebagai Media Pembelajaran (Studi Evaluasi Model Pembelajaran E-Learning Smk Telkom
Sandhy Putra Purwokerto). Jurnal Pendidikan Vokasi, 3(1). 